\section{Kastamonu Eğitim Dergisi Kastamonu Education Journal}

Mart 2019 Cilt:27 Sayı:2

kefdergi.kastamonu.edu.tr
Başvuru Tarihi/Received: 30.01 .2018

Kabul Tarihi/Accepted: 04.05.2018

DOI: $10.24106 /$ kefdergi.2622

\title{
Örüntü Arama Stratejisi İle Çözülebilecek Problemleri Kurmada Ortaokul Öğrencilerinin Performanslarının İncelenmesi
}

\section{Investigation of the Performance of the Middle School Students in the Posing of Problems That Can Be Solved By The Looking for A Pattern Strategy}

\author{
Çiğdem KILIÇ
}

\section{Öz}

Bu çalışmaya toplam 189 ortaokul 8. sınıf öğrencisi katılmış olup, bu öğrencilerin problem çözme stratejilerinden biri olan örüntü arama stratejisi ile çözülebilecek problem kurma performanslarının belirlenmesi amaçlanmıştr. Bu amaç doğrultusunda öğrencilere örüntü arama stratejisi ile çözülebilecek problem kurmaları ve bu problem kurma sürecinde neler yaptıklarını adım adım anlatmaları istenmiştir. Çalışmaya katılan öğrencilerden gönüllü olan ve başarı düzeylerine göre farklılık gösteren toplam 6 öğrenci ile de klinik görüşmeler gerçekleştirilmiştir. Çalışmadan elde edilen verilerin analizinde semantik ve betimsel analiz teknikleri kullanılmıştır. Araştırmadan elde edilen sonuçlara bakıldığında, katlımcıların büyük çoğunluğu örüntü arama stratejisi ile çözülebilecek problem kurma yerine örüntü oluşturma yoluna gitmişlerdir. Örüntü arama stratejisi ile çözülebilecek problemlerin yapısına bakıldığında ise öğrencilerin daha çok lineer sayı örüntüsü türüne başvurdukları görülmektedir.

Anahtar Kelimeler: problem kurma, problem çözme stratejisi, örüntü arama stratejisi, ortaokul öğrencisi

\begin{abstract}
A total of 189 middle school 8th grade students participated in this study and it was aimed to determine the problem posing performances of these students that can be solved by the look for a pattern strategy which is one of the problem solving strategies. For this purpose, students are asked to pose problems that can be solved with the look for a pattern strategy and to explain step by step what they are doing in the process of posing this problem. Clinical inter-views were conducted with 6 students who were volunteers from the study participants and who differed according to their level of achievement. Descriptive and semantic analysis techniques were used in the analysis of the data obtained from the study. According to the results of the study it can be concluded that the vast majority of participants tended to give pattern examples rather than the problems that could be solved by the look for a pattern problem solving strategy. When we look at the structure of the problems that can be solved by the loook for a pattern strategy, it is seen that the students apply more linear number patterns
\end{abstract}

Keywords: Problem posing, problem solving strategy, look for a pattern strategy, middle school student 


\section{Extended Summary}

Problem posing involves many skills, such as formulating everyday problems and mathematical situations, using a suitable approach to pose problems for mathematical situations, and recognizing relationships among different mathematics topics (Abu-Elwan, 1999). Problem posing and its process is defined by many researchers and mathematics educators (Stoyanova \& Ellerton 1996; Tichá \& Hošpesová, 2009). Problem posing is as the creation of new problems or the reformulation of a given problem (Tichá \& Hošpesová, 2009). A similar definition was presented by Stoyanova and Ellerton (1996, p.518), who defined problem posing as "the process by which, on the basis of mathematical experience, students construct personal interpretations of concrete situations and formulate them as meaningful mathematical problems".

There are many different types of problem posing activities. The literature indicating problem posing frameworks most of the studies focused on mathematical topics, operations or representations and problem solving time (before, during or after). So there are no studies that associate with the problem posing and problem-solving strategies belonging to problem solving process.This study analyzes middle school students' problem posing performance requiring problem solving strategy knowledge. There are many different problem solving strategies mentioned in the literature such as construct a table or chart, find a pattern, draw a picture or diagram, solve a simpler problem, guess and check, working backwards, write an open sentence, logical reasoning (Cathcart et al., 2003; Souviney, 1994), make a systematic list, construct a general rule, add something to the problem situation (Souviney, 1994). Among those strategies finding a pattern as a problem solving strategy is an important problem solving strategy due to its relation to pattern as a mathematical topic and being one of the most used problem solving strategies.

Participants were asked to pose problems which can be solved by looking for a pattern problem solving strategy. In the study, data were collected in two steps. First of all, a problem posing task that consisted of two questions were applied by 189 middle school students and then task-based interviews were conducted with six participants among those students. The results of the study showed that less than half of participants were able to pose word problems which can be solved using looking for a pattern problem solving strategy. Moreover, vast majority of participants tended to give pattern examples rather than the problems that could be solved by the look for a pattern problem solving strategy. When we look at the structure of the problems that can be solved by the loook for a pattern strategy, it is seen that the students apply more linear number patterns than non-linear number patterns. Moreover, some of the participants faced issues while posing problems.

This study is about problem posing activity which can be solved by looking for a pattern strategy from problem solving strategies. Problem posing studies that can be solved with other strategies such as making a table or finding a general rule from problem solving strategies can be done in future studies. In addition to this, they can also be investigated what they are pursuing and how they pay attention to the problem posing process. Performance that students have exhibited may also have been affected by affective factors. For this reason, further studies may include studies associated with students' attitudes towards problem-solving and posing. 


\section{Giriş}

Problem kurma matematik eğitiminde önemli bir yere sahip olan ve bir takım zihinsel etkinlikleri yerine getirmeyi gerekli kılan önemli bir süreçtir. Problem kurma etkinliklerinin hangi düzeyde olursa olsun matematik yapabilmekten daha çok şeyi içerdiği belirtilmektedir (Pirie, 2002). Problem kurma etkinliği öğrencilere kendi problemlerini desenleyen ya da kendi oluşturdukları problemleri başkalarına sorabilecekleri hissini vermektedir (Rizvi, 2004). Bunun yanı sıra, problem kurma temelli bir problem çözme eğitimden geçen ilköğretim öğrencilerinin özellikle kendi oluşturdukları problemlerde geçen çözüme yönelik eksik, fazla veya gizli bilgileri saptamaları ve yazdıkları problemin mantiksallığını irdelemeleri, öğrencilerin niteliksel akıl yürütme becerilerini geliştirdiği ve buna bağlı olarak da problemi anlama başarılarını üst düzeye çıkardı̆̆ı belirtilmektedir (Cankoy ve Darbaz, 2010).

Alanyazında problem kurma ile ilgili farklı tanımlara yer veriliği görülmektedir. Problem kurma yeni problemler üretme ya da verilen bir problemi yeniden oluşturmadır (Tichá \& Hošpesová). Problem kurma belirli koşullar altında öğrencilerin problemler oluşturmasını içerebileceği gibi, var olan üzerinde çalışılan problemlerin değiştirilerek bunlardan yeni problemler oluşturulmasını da kapsar (Silver, 1994). Problem kurma farklı biçimlerde tanımlansa da, her tanımda ortak olan nokta, yeni problemler üretmektir. Ambrus (1997) problem kurmayı bir durum veya deneyimden yeni problemler oluşturma şeklinde tanımlamıştr. Problem kurma problem çözmeden önce, verilen durumdan problemler oluşturma biçiminde-problem çözme süreci içerisinde (veya problem çözüldükten sonra gerçekleştirilen) değişen uygulama biçimleri ve türleri bulunan bir etkinlik olmaktadır (aktaran Ev-Çimen ve Yıldız, 2017).

Gonzales (1998) ise problem kurmayı, George Polya'nın dört aşamalı olan problem çözme sürecinin beşinci aşaması olarak nitelendirmiştir. Burada öğrenciler de çözdükleri probleme bakarak problemde değişme ya da ekleme yaparak problem kurmaları istenmektedir. Ortaokul matematik dersi (5-8. sınıflar) öğretim programında öğrencilerin problem çözme becerilerini geliştirmeye yönelik çalışmalarda; (1) problemi anlama, (2) çözümü planlama, (3) planı uygulama, (4) çözümün doğruluğunu ve geçerliğini kontrol etme ve (5) çözümü genelleme ve benzer/özgün problem kurma süreçleri gözetilmelidir vurgusu yapılmakta olduğu görülmektedir (MEB, 2013). Gonzales (1998) ve Ortaokul Matematik Dersi Öğretim Programına (MEB, 2013) bakıldığında problem kurma çalışmalarına dört aşamalı problem çözme sürecinden sonra yer verildiği, dolayısıyla problem çözme strateji bilgisine sahip bireyler olarak öğrencilerden, problem kurmaları beklenmekte olduğu söylenebilir.

Problem çözme sürecinde çözüm planı yaparken öğrenciler bu aşamada problem çözme stratejisini belirlemekte ve bunu problem çözme basamağının planı uygulama aşamasında uygulamaktadırlar. Bu nedenle başarılı bir problem çözme olabilmesi için problem çözme strateji bilgisi önemli bir yere sahiptir. Problem çözme stratejilerinin neler olduğuna bakıldığında, tablo yapma, örüntü arama, resim ya da diyagram çizme, basit bir problem çözme, tahmin kontrol, geriye doğru çalışma, muhakeme etme, denklem yazma, (Cathcart ve diğerleri, 2003; Souviney, 1994), liste yapma, genel kuralı bulma ve problem durumuna ekleme yapma (Souviney, 1994) gibi stratejilerin olduğu göze çarpmaktadır.

Durmaz ve Altun (2014) tarafindan yapılan ortaokul öğrencilerinin problem çözme stratejilerini kullanma düzeyleri ile ilgili araştırmadan elde edilen sonuçlara bakıldığında en yüksek kullanım yüzdesi bağıntı (örüntü) arama ve sıra dışı bölme problemlerinde; en düşük kullanım yüzdesi ise sırasıyla tablo yapma, eleme ve diyagram (şekil) çizme stratejilerinde ortaya çıkmıştır. Gür ve Hangül (2015) tarafindan yapılan ortaokul öğrencilerinin problem çözme stratejileri üzerine bir çalışmada ise öğrencilerin örüntü arama, sondan başlama, denklem yazma ve liste hazırlama stratejilerini içeren soruları doğru cevapladıkları belirlenmiştir. Bu stratejilerden örüntü arama stratejisi öğrenciler tarafindan problem çözmede sıklıkla başvurulan bir strateji olduğu görülmektedir. Örüntü arama özellikle cebirsel düşünme alanında pek çok etkinliklerin kalbidir. Sayı ve işlemlerdeki örüntüler ortaokuldan lise yıllarına kadar pek çok konunun öğretiminde önemli bir yere sahiptirler (Van De Walle, 2004).

Örüntü arama stratejisinde sayı ve geometrik örüntüleri arama, problem durumundaki yapısal ilişkiler hakkında ipuçları sağlamaktadır (Souviney, 1994). Örneğin "Küçük bir adada toplam 1000 insan yaşamaktadır. Ada nüfusu her 30 yılda bir iki katına çıkmaktadır. Buna göre, 30 yıl sonra, 60 yıl sonra, 300 yıl sonra adanın nüfusu kaç olacaktır? Ada nüfusu ne zaman 1 milyonun üzerinde olacaktı?" probleminin çözümünde örüntü arama stratejisi kullanılabilir (Reys ve diğerleri, 1998), çünkü ada nüfusunun artş̧ında belli bir düzen vardır.

Örüntü arama stratejisi kullanılırken pek çok örüntü türüne başvurulabilmektedir. Örüntü türlerini neler olduğu ile ilgili çalışmalara bakıldığında, Stacey (1989) örüntüyü $n$.inci terimin ifade ediliş biçimine göre an+b lineer ve $a n^{2}+b n+c$ kuadratik-lineer olmayan olarak sınıflamıştır. Smith (1997) ise örüntüyü sayısal ve sayısal olmayan biçiminde ikiye ayırmıştır. Bazı araştırmacılarda örüntüler tekrarlayan ya da genişleyen biçiminde sınıflandırmıştı (Cathcart ve diğerleri, 2003; Mulligan ve Mitchelmore, 2009; Reys ve diğerleri, 1998; Van De Walle, 2004; Warren ve Cooper, 2006). Smith 
(2013) ise örüntüyü tekrarlayan, genişleyen ve ilişkisel örüntüler biçiminde sınıflandırmıştır. Tekrarlayan örüntüde çekirdek öğe tekrarlar ve örüntünün daha büyük öğelerini oluşturmak için kullanılır. Tekrarlayan örüntüye, "do, mi, mi, do, mi, mi,... (Van De Walle, 2004), ya da A-B-A-B-A-B, örnek olarak verilebilinirken (Warren ve Cooper, 2006), genişleyen örüntüye de 2, 4, 6, 8, . . ve 1, 2, 4, 8, 16 örnek olarak verilebilir (Burns, 2007). ilişsisel örüntüde iki küme arasında bağlant kurulur. Örneğin, 1-8, 2-16, 3-24 ve bu iki küme arasındaki ilişki bir tabloda gösterilebilir (Smith, 2013). Örüntü arama stratejisi bilgisine sahip olma hem problem çözme, hem de problem kurma açısından önemlidir.

Alanyazında problem kurma çalışmaları ile ilgili çeşitli sınıflamalar mevcuttur (Silver ve Cai, 1996; Stoyanova ve Ellerton, 1996; Christou ve diğerleri, 2005; Kılıç, 2013; Kılıç, 2017). Silver ve Cai (1996) problem kurmayı çözüm öncesi çözüm içinde ve çözüm sonrası problem kurma biçiminde ele almıştr. Stoyanova ve Ellerton (1996) ise problem kurma durumunu serbest, yarı-yapılandııımış ve yapılandırılmış olarak üçe ayırmışlardır. Bu sınıflamada doğal bir duruma göre problem üretme, açık-uçlu problemler, verilen problemlere benzer problemler, çözümleri benzer olan problemler, özel teoremlerle ilgili olan problemler, verilen resimlerden üretilen problemler ve sözel problemlerdir (AbuElwan,1999). İyi yapılandırılmış bir problem ya da problem durumu verilir ve verilmiş problem ya da çözüme uygun problem kurmaları istenir (Stoyanova ve Ellerton, 1996). Stoyanova ve Ellerton'nun (1996) sınıflamasında yer alan yapılandırılmış ve yarı-yapılandırılmış problem kurma etkinliklerini benimseyerek bilişsel süreçleri de içeren bir başka sınıflamayı da Christou ve diğerleri (2005) geliştirmiştir. Bu sınıflamada düzenleme, seçme, kavrama ve aktarma süreçleri önemlidir. Bu sınıflamada problem kurma etkinliği bir hikâye ya da resim verilerek, yanıtlara uygun problem kurma, matematiksel denklemler ya da hesaplamalara dayalı olarak problem kurma, problemleri grafik, diyagram ya da tablolara bağlı olarak kurmadır. Kılıç (2013) ise, Stoyanova ve Ellerton (1996) tarafindan geliştirilen serbest, yarı-yapılandırılmış ve yapılandırımış problem kurma çalışması ve Christou ve arkadaşları (2005) tarafindan öne sürülen modelde yer alan kavrama, aktarma, düzenleme ve seçme alt boyutları benimseyerek problem kurma etkinliklerini serbest (bir konu verilmeden ve bir konu verilerek), yarı-yapılandırılmış (düzenleme ve aktarma) ve yapılandırılmış (kavrama ve seçme) olarak sınıflamıştr. Kılıç (2017) sınıf öğretmeni adayları ile yaptı̆̆ çalışmasında problem çözme stratejisi temelli problem kurma çalışmasına yer vererek problem çözme sürecinde önemli bir yeri olan problem çözme stratejini de ön plana çıkaran bir problem kurma sınıflaması önermiştir.

Ortaokul öğrencileri ile problem kurma üzerine yapılan çalışmalara bakıldığında genelde matematikte yer alan konu (Çelik ve Yetkin-Özdemir, 2011), ve kavramlara (Işık ve Kar, 2015; Şengül-Akdemir ve Türnüklü, 2017), ya da öğrencilerin tutum gibi bilişsel özellikleri (Özgen, Aydın, Geçici ve Bayram, 2017), ile ilişkilendirilen çalışmalara yer verildiği ancak, öğrencilerin problem çözme stratejisi bilgisini ortaya çıkarma potansiyeline sahip olan problem çözme stratejisi temelli problem kurma çalışmalarına pek yer verilmediği görülmektedir. Bu çalışmada problem çözme strateji bilgisi ortaya çıkarılması hedeflendiğinden öğrencilerin problem çözme strateji bilgilerinin gelişmesine de katkı getireceği umulmaktadır. Illeride bu türden çalışmalar yapıldığında öğrenciler yalnızca konu, kavram, işlem ya da bağlama bağlı kalmadan kurdukları problemlerin hangi strateji ile çözülebileceği konusunda fikir sahibi olmaları da sağlanmış olacaktır.

\section{Araştırmanın Amacı}

Bu çalışmanın amacı ortaokul 8. sınıf öğrencilerinin problem çözme stratejilerinden biri olan örüntü arama stratejisi ile çözülebilecek problem kurma performanslarını belirlemektir. Bu çalışmada problem çözme stratejisi temelli problem kurma çalışmasına yer verilmesinin nedeni öğrencilerin kurmuş oldukları problemlerin onların problem çözme stratejisi, örüntü, problem kurma matematiksel bilgilerini yansıtma potansiyeline sahip olmasıdır.

Bu çalışma ile şimdiye kadar yapılan problem kurma çalışmalarının dışına çıkılarak öğrencilerin problem çözme stratejisi bilgisi gerektiren problem çözme stratejisi temelli problem kurma çalışmalarına yer verilmiştir. Böylece öğrencilerin gerek problem kurma ile ilgili, gerekse problem çözme stratejileri ile ilgili bilgileri ölçülerek ortaya çıkan sorunların çözümüne yönelik öneriler geliştirilmeye çalışılmıştır.

\section{Araştırmanın problemi}

Bu amaç doğrultusunda aşağıdaki soruya yanıt aranmıştır;

- Ortaokul 8. sınıf öğrencilerinin örüntü arama stratejisi temelli problem kurma çalışmalarındaki performansları nasıldır?

\section{Yöntem}

Bu çalışmada var olan durum ortaya çıkarılmaya çalışılmış ve belli öğrencilerle de klinik görüşmeler yapılmıştır. 


\section{Katılımcılar}

Çalışmanın birinci aşamasına toplam 189, ikinci aşamasına da toplam alt ortaokul 8. sınıf öğrencisi katılmıştr. Öğrenciler ortaokul 8. Sınıf öğrencisi olup, yaşları 14-15 yaşları arasında değişmektedir. Klinik görüşme yapılacak olan öğrencilerin seçiminde amaçlı örnekleme yöntemlerinden ölçüt örnekleme yöntemi benimsenmiştir. Çalışmada klinik görüşmelere kattlan öğrencilerin seçiminde gönüllü olmasının yanı sıra başarı düzeylerinin farklı (2yüksek, 2 orta ve 2 düşük) olmasına da dikkat edilerek seçim yapılmıştır. Başarı düzeyleri belirlenirken matematik dönem notları ve matematik öğretmeninin görüşü temel alınmıştır.

Çalışmada ortaokul 8. sınıf öğrencilerine yer verilmesinin nedeni ortaokulda öğrendikleri problem, problem kurma, problem çözme stratejisi ile ilgili temel bilgilerinin genel bir değerlendirmesini yapmaktr. Ayrıca bu öğrenciler örüntüleri tanıma, devam ettirme, örüntü oluşturma ve örüntülerin genel kuralını bulma çalışmalarını yapmış öğrencilerdir. Bu nedenle bu öğrencilerin örüntü, problem çözme ve kurma ile ilgili temel bilgilere sahip oldukları düşünülmektedir. Bu nedenle, bu çalışmada öğrencilerin bu bilgilerini kullanma durumları da ortaya çıkarılmaya çalışımıştır.

Klinik görüşme yapılan öğrencilerin gerçek isimleri kullanılmamış onun yerine öğrencilerin isimleri, başarı düzeylerine göre, kodlama yoluna gidilmiştir. $\mathrm{i}_{1}, \mathrm{i}_{2^{\prime}} \mathrm{O}_{1^{\prime}}, \mathrm{O}_{2^{\prime}} \mathrm{D}_{1}$ ve $\mathrm{D}_{2}$ ve görüşmeci de $\mathrm{G}$ olarak kodlanmıştr.

\section{Veri toplama süreci}

Çalışmada veriler iki aşamada toplanmıştır. Çalışmanın birinci aşamasında veri toplamak için öğrencilere yazılı bir formada iki sorudan oluşan bir problem kurma görevi verilmiştir. Bu görevde örüntü arama stratejisi ile çözülebilecek bir problem kurunuz ve bunu yaparken neler yaptı̆̆ınızı adım adım anlatınız biçiminde sorular sorulmuş olup, öğrencilerin yanıtları yazılı olarak alınmıştı. Çalışmanın ikinci aşamasında ise öğrencilerden alınan yanıtlara ve öğrencilerin başarı durumlarına göre altı öğrenci ile de klinik görüşmeler gerçekleştirilmiştir...

Problem kurma görevinin ve klinik görüşme sorularının anlaşılır olup olmadığı ve öğrencilerin düzeylerine uygun olup olmadığını ortaya çıkarmak için bir matematik eğitimcisinin görüşlerine başvurulmuş olup, bu soruların öğrencilerin düzeylerine uygun olduğu ve anlaşılır olduğu yönünde görüş alınmıştır. Daha sonra benzer bir gruba problem kurma görevi sunularak ve görüşme soruları da iki öğrenciye sorularak pilot çalışmaya yer verilmiştir. Pilot çalışma sonucunda anlaşılır olmayan bir görüşme sorusu çıkarılmıştr. Görüşmeler sırasında katılımcılara "örüntü arama stratejisi ile çözülebilecek bir problem kurman istenmişti. Bu süreçte neler yaptın adım adım anlatır mısın?, Bu problemi kurarken zorluk yaşadın mı?, Sence bu bir problem midir? Peki oluşturduğun bu problem örüntü arama stratejisi ile çözülebilir mi? Oluşturduğun problemi genel anlamda değerlendirir misin? şeklinde sorular yöneltilmiştir. Görüşmeler toplam 15-20 dakika arasında sürmüştür. Tüm görüşmeler kayıt altına alınmıştır.

\section{Veri Analizi}

Araştırmadan elde edilen veriler iki aşamada analiz edilmiştir. Birinci aşamada elde edilen verilerin analizinde semantik analiz tekniği ve betimsel analiz tekniği kullanıımıştı. Semantik analiz sırasında öğrencilerin oluşturdukları problemler/durumlar örüntü arama stratejisi ile çözülebilme durumlarına göre sınıflandırılmıştı. Daha sonra bu kodlanan verilerin frekans ve yüzde hesaplaması yoluna gidilmiştir. Veri analizinin ikinci aşamasında klinik görüşmelerden elde edilen veriler betimsel analiz tekniği ile analiz edilmiştir. Nitel verilerin analizinde Miles ve Huberman (1994) tarafindan geliştirilen sınıflama kullanılmıştır. Bu sınıflamaya göre veriler "verinin işlenmesi", "verinin görsel hale getirilmesi" ve "sonuç çıkarma ve teyit etme" bölümlerinden oluşan bir sınıflama benimsenmiştir. Analizin verinin işlenmesi aşamasında veri dökümünde yer alan veri seçilmiş incelenmiş ve araştırma problemine göre en önemli olan veriler seçilerek kodlanmıştır. Veriler araştırmacı ve bir alan uzmanı tarafindan bağımsız olarak analiz edilmiştir. Kodlayıcılar arası güvenirlik \%94 olarak belirlenmiştir. Kodlayıcılar arası güvenirlik hesaplanırken Miles ve Huberman (1994)'ın önerdiği formül olan Güvenirlik = Görüş Birliği / (Görüş Birliği + Görüş Ayrılığı) formülü kullanılmıştır.

Verinin görsel hale getirildiği ikinci aşamada ise kodlanan veriler birbirleriyle ilişkilendirilerek şekil halinde sunulmuştur. Sonuç çıkarma ve teyit etme aşamasında ise kodlanan veriler yorumlanmış ve birbirleriyle karşılaştırılmıştı. Bu karşılaştırmalar öğrenci görüşmelerinden doğrudan alıntılar yapılarak desteklenme yoluna gidilmiştir.

\section{Bulgular}

Ortaokul 8. sınıf öğrencilerinin örüntü arama stratejisi temelli problem kurma performansına yönelik bulgular ( $N=$ frekans, \%=yüzde)

Ortaokul öğrencilerinin örüntü arama stratejisi temelli problem kurmaya yönelik olarak yanıtları Şekil 1'de verilmiştir. 


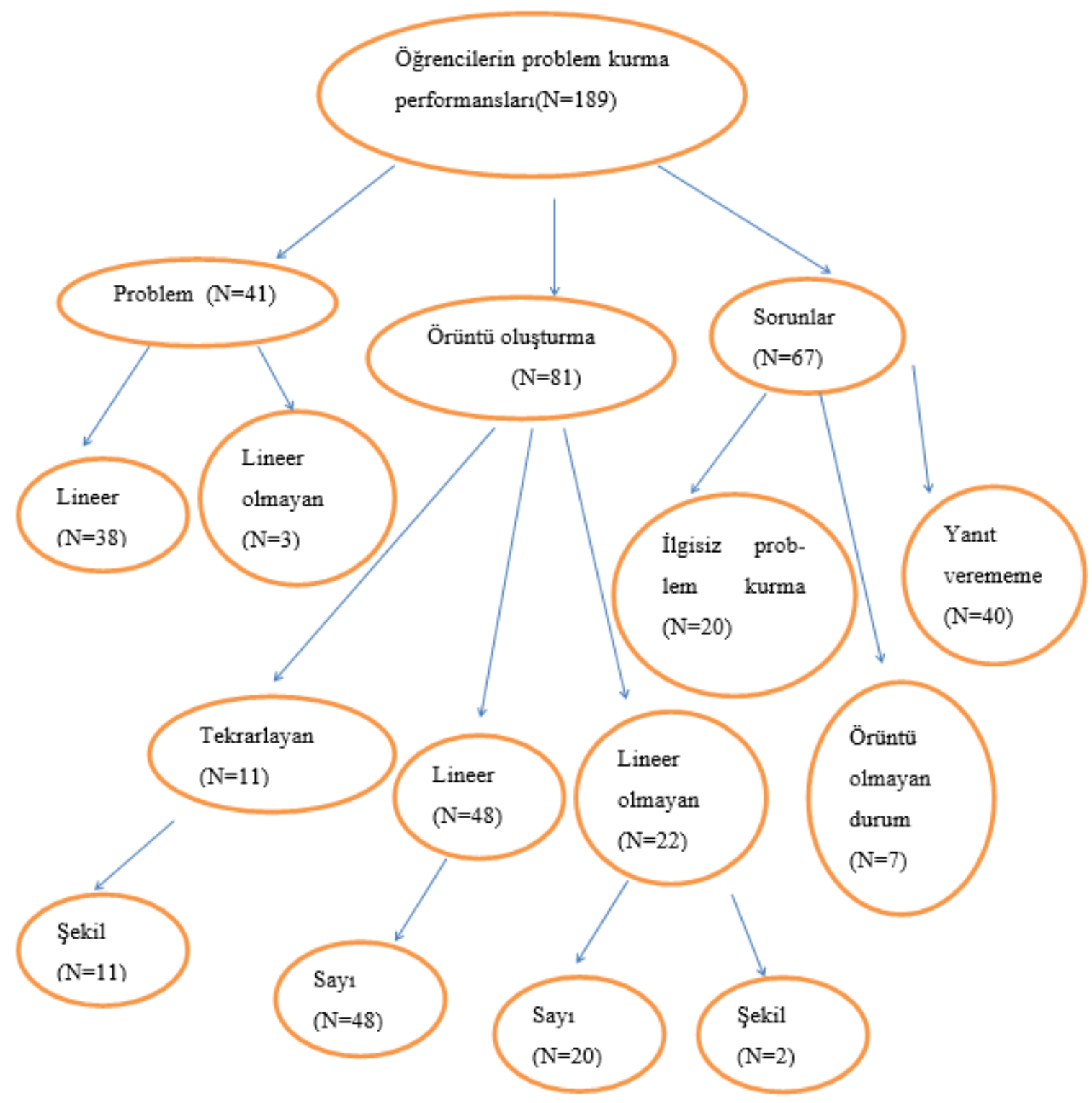

Şekil 1. Ortaokul öğrencilerinin problem kurma performansları

Şekil 1'den görüldüğü gibi, ortaokul 8. sınıf öğrencileri örüntü arama stratejisi ile çözülebilecek problemler $(\% 21,69)$ kurmuşlardır. Öğrenciler tarafindan kurulan problemlerin yapısına bakıldığında lineer $(\% 20,10)$ ve lineer olmayan $(\% 1,58)$ problemler oldukları belirlenmiştir. Öğrencilerin kurmuş oldukları problem örnekleri ve öğrencilerle yapılan görüşmelerden alıntılar aşağıdaki gibidir:

Lineer örüntü problemine örnek:

$$
\begin{aligned}
& \text { Bir erik ağacl dikil diginde toocm veher hatta } \\
& \text { go cm vzugor. Buna góne } 133 \text { gün sonra erik } \\
& \text { agaacının bogu kag om olor? }
\end{aligned}
$$

Bir erik ağacı dikildiğinde $100 \mathrm{~cm}$ ve her hafta $90 \mathrm{~cm}$ uzuyor. Buna göre 133 gün sonra erik ağacının boyu kaç cm olur?

G: Senden örüntü arama stratejisi çözülebilecek bir problem kurman istenmişti. Sen de böyle bir durum yazmışsın. Sence bu bir problem midir? Neden?

$\mathfrak{i}_{1}$ : Bence bir problemdir. Çünkü verilmeyenler var onların bulunması lazım. Soru oluşturuyor kafamızda. 
Çözülebiliyor.

G:Peki sence örüntü arama stratejisi ile çözülebilir mi?

$\mathfrak{I}_{1}$ : Evet dediğim gibi. Belli bir düzen içerisinde ilerliyor ağacın büyümesi. Her hafta $90 \mathrm{~cm}$ ve 133 kaç hafta eder ona göre bir çözüm oluyor.

G: Oluşturduğun bu problem genel anlamda değerlendirir misin?

$\mathfrak{I}_{1}$ :Daha önceden benzer problemler görüyordum kitaplardan. Kendim yazdım bu soruyu ve çözülebileceğine inanıyorum.

Katılımcılardan $\mathrm{i}_{1}$ örüntü arama stratejisi ile çözülebilecek olan bir problemi doğru bir biçimde kurmuştur. Bu problemi kurarken de sabit artan lineer yapıda bir örüntü örneğinden yararlanmıştır.

Lineer olmayan örüntü problemine örnek: Ege her gün kitap okuma kararı almıştr. İlk gün 15 sayfa okumuştur. Diğer günler ise ilk gün okuduğunu 5'er sayfa arttrarak devam etmiştir. Ege 10. günde kaç sayfa kitap okumuştur?

Kathlımcılardan $\mathrm{i}_{2}$ ise bu yazdığının bir problem olduğunu ve düşünmeyi gerektirdiğini insanlarda bir merak uyandırdığı için problem olduğunu ifade etmiştir. Bu probleme benzer problemler çözdükleri için daha önce benzer bir problem kurmak istediğini belirtmiştir.

Bunun yanı sıra, öğrenciler problem durumu olmayan örüntüler de $(\% 42,85)$ de oluşturmuşlardır. Bu oluşturulan örüntüler, örüntü türlerinden tekrarlayan şekil örüntüsü $(\% 5,82)$, lineer sayı örüntüsü $(\% 25,39)$, lineer olmayan sayı $(\% 10,58)$ ve şekil $(\% 1,05)$ örüntüsüdür.

Tekrarlayan şekil örüntüsüne örnek:

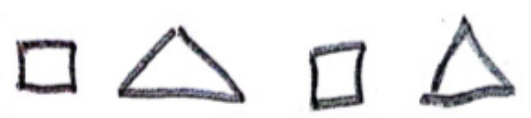

G: Senden örüntü arama stratejisiyle çözülebilecek bir problem kurman istenmişti. Sen de böyle bir örnek sunmuşsun. Sence bu problem örüntü arama stratejisi ile çözülebilir mi? Neden?

$\mathrm{O}_{2}$ : Evet bir örüntüdür. Kare üçgen ve gene kare üçgen diye gidiyor.

G: Anladım. Peki problem mi sence?

$\mathrm{O}_{2}$ : Aslında problem de denilebilir. Bu örüntüyü devam ettirecek ama emin değilim.

G: Peki problem mi değil mi? Bu yazdıkların sence?

$\mathrm{O}_{2}$ : Olabilir de olmayabilir de.

Katılımcılardan $\mathrm{O}_{2}$ sözel bir problem kurmak yerine tekrarlayan şekil örüntüsü oluşturma yoluna gitmiştir.

Lineer sayı örüntüsüne örnek:

$3,6,9,12,15,18, .$.

G: Sence bu bir problem midir?

$D_{2}$ : Evet öyledir.

G: Neye göre söylüyorsun bunu peki? Açıklar mısın?

$\mathrm{D}_{2}$ :Sınıfimızda yapmıştık buna benzer bir soru. Öğretmen sormuştu.

G:Peki bu oluşturduğun problem ise, sence örüntü arama stratejisi ile çözülebilir bir problem midir?

$\mathrm{D}_{2}$ :Bilmiyorum. Nasıl olacak bilmiyorum.

Katlımcılardan $\mathrm{D}_{2}$ sözel bir problem kurmak yerine, sabit artan bir sayı örüntüsü örneği sunmuştur. Bu oluşturduğu durumun problem olup olmadığını da bilmediği belirlenmiştir.

Lineer olmayan sayı örüntüsüne örnek:

$$
4,7,11,16,22, . .
$$

Katılımcılardan biri sabit olarak artmayan bir sayı örüntüsü örneği sunmuştur kendisinden örüntü arama stratejisi ile çözülebilecek problem kurması istenmesine rağmen. 
Lineer olmayan şekil örüntüsüne örnek:

\section{曰・ロロロロ ロロロロロロロロロ}

G: Örüntü arama stratejisi ile çözülebilecek problem kurman istenmişti sende böyle bir örnek sunmuşsun?

Sence bu bir problem midir? Nedeni açıklar mısın?

$\mathrm{O}_{1}$ : Böyle karelerden oluşan bir örnek sunmak istedim.

G: Peki problem mi?

$\mathrm{O}_{1}$ : Öğrenci devam ettirecek. Başka bilemedim. Ya da bir kare, iki kare, üç kare de devam edebilirdi. Problem bence.

G:Peki bu oluşturduğun yapı eğer bir problem ise, örüntü arama stratejisi ile çözülebilir mi?

$\mathrm{O}_{1}$ : Örüntü arama stratejisi denilince aklıma pek bir şey gelmiyor.

Katılımcılardan $\mathrm{O}_{1}$ örüntü arama stratejisi ile çözülebilecek problem yerine lineer olmayan şekil örüntüsü örneği vermiştir.

Bu çalışmada ortaokul 8. sınıf öğrencilerinin ilgisiz problem kurma $(\% 10,58)$, örüntü olmayan durumlara $(\% 3,7)$ yer verme ve yanıt verememe $(\% 21,16)$ gibi sorunlar yaşadıkları da belirlenmiştir.

İlgisiz problem kurmaya örnek: Ayşe'nin 3 kutu dolusu bilyesi vardır. 1 kutusunu Fatma'ya verir ise Ayşe'nin kaç kutu bilyesi kalır?

G: Senden örüntü arama stratejisi çözülebilecek bir problem kurman istenmişti. Sen de böyle bir örnek vermişsin. Sence bu oluşturduğun problem örüntü arama stratejisi ile çözülebilecek bir problem midir?

$\mathrm{D}_{1}$ : Evet çözülür bence bir problem bu sayılar var soru sorma var.

G: Peki örüntü arama stratejisi ile çözülebilecek problem derken ne kastediliyor sence?

$D_{1}$ : Çözülebilecek bir problem çözülür ama onu bilmiyorum.

Katilımcılardan $\mathrm{D}_{1}$ sözel bir problem kurmuştur ancak bu problem örüntü arama stratejisi ile çözülebilecek bir problem değildir.

Örüntü olmayan duruma örnek:

$$
1,2,3,1,4,1,2,1,1,4
$$

Katılımcılardan biri de örüntü olmayan bir örnek sunmuştur.

\section{Sonuçlar}

Yapılan çalışmalar göstermektedir ki, problem kurma çalışmaları hem öğrencilere, hem de öğretmenlere sağladığı yararlar bakımından matematik eğitiminde önemli bir yere sahiptir. Önemli bir konu olmasından dolayı problem kurma pek çok araştırmacının ilgisini çekmiş ve bugüne kadar farklı problem kurma çalışmaları yapılmıştır. Problem kurma çalışmaları ile ilgili olan sınıflamalara bakıldığında farklııklar göze çarpmaktadır (Silver ve Cai, 1996; Stoyanova ve Ellerton, 1996; Christou ve diğerleri, 2005; Kılıç, 2013; Kılıç, 2017). Bu sınıflamalarda öğrencilerden daha çok matematiksel bir konu, bağlam, işlem ya da temsil biçimi gibi değişkenlere göre problemler kurmaları istenmektedir. Bunun yanı sıra, problem kurma üzerine ortaokul öğrencileri ile yapılan çalışmalarda da matematikte yer alan konu (Çelik ve Yetkin-Özdemir, 2011), kavram (Işık ve Kar, 2015; Şengül-Akdemir ve Türnüklü, 2017), ya da öğrencilerin bilişsel özellikleri (Özgen, Aydın, Geçici ve Bayram, 2017), ile ilişkilendirilen çalışmaların olduğu görülmektedir. Hem problem kurma ile ilgili yapılan sınıflamalarda, hem de ortaokul düzeyindeki öğrencilerle yapılan problem kurma çalışmalarında matematiksel konu, kavram, işlem ve duyuşsal özellikleri dikkate alan problem kurma çalışmalarına yer verildiğiği,öğrencilerin problem çözme stratejisi bilgisini ortaya çıkarma potansiyeline sahip olan problem çözme stratejisi temelli problem kurma çalışmalarına pek yer verilmediği görülmektedir. Öğrencilerin kurdukları problemleri nasıl çözecekleri konusunda sahip olmaları gereken problem çözme strateji bilgisi hem problem çözme, hem de problem kuram çalışmaları için önemlidir.

Çalışmadan elde edilen sonuçlara bakıldığında, öğrencilerin örüntü arama stratejisi ile çözülebilecek problem kurma performanslarının (\%21.69) düşük olduğu görülmektedir. Bu durumda öğrencilerin problem çözme stratejilerinden örüntü arama strateji bilgilerinin eksik olduğu söylenebilir. Problem çözme stratejileri üzerine yapılan çalışmaların sonuçlarına bakıldığında (Durmaz ve Altun, 2014; Gür ve Hangül, 2015) örüntü arama stratejisi ile çözülebilecek problemlerin öğrencilerin karşısına sıkça çıktığı belirtilmektedir. Bu nedenle öğrencilerin problem çözme strateji içerisinde yer 
alan örüntü arama stratejisi bilgilerinin geliştirilmesi gerektiği söylenebilir.

Öğrencilerin kurmuş olduğu ve örüntü arama stratejisi ile çözülebilecek olan problemlerin yapısına bakıldığında öğrencilerin ağırlıklı olarak lineer örüntüye örnek teşkil edecek problemler kurmayı tercih ettikleri, lineer olmayan örüntü problem durumlarına daha az yer verdikleri belirlenmiştir. Örüntü türlerinden tekrarlayan ya da ilişkisel örüntü türlerine problem kurma durumlarında yer vermedikleri de belirlenmiştir.

Çalışma sırasında öğrenciler daha çok örüntü oluşturma yoluna gidip, problem kurmayı pek gerçekleştirememişlerdir. Bunun bir nedeni de öğrencilerin problem ile ilgili sahip oldukları bilgi olabilir. Örüntü türlerinden lineer sayı örüntüsünü daha çok oluşturma yoluna gitmişlerdir. Bunun yanı sıra ilgisiz problem kurma, örüntü olmayan durum sunma ve yanıt verememe gibi sorunlarla da karşılaştikları görülmektedir. Öğrencilerin problem kurma sırasında örüntü arama stratejisi ile problem kuramamalarııın nedeni daha önceden bu türden çalışmalara yer vermemiş olmaları ile açıklanabilir.

Öğrencilerin bu tarz çalışmalara yer vermemiş olmamaları öğrencilerin performanslarını etkilemiş olabilir bu nedenle problem çözme stratejisi temelli problem kurma çalışmalarına daha çok yer verilmelidir. Kılıç'ın (2017) da belirttiği gibi, problem kurmanın öğrencileri değerlendirmede etkili bir yol olduğu düşünüldüğünde problem çözme stratejisi temelli problem kurma çalışmaları yapılarak öğrencilerim problem, problem çözme stratejisi, problem kurma bilgileri daha derinlemesine ortaya konulabilir.

\section{5. Öneriler}

Örüntü arama stratejisinde sayı ve geometrik örüntüleri arama, problem durumundaki yapısal ilişkiler hakkında ipuçları sağlamak (Souviney, 1994) olduğu düşünüldüğünde öğrencilere sayı ve geometrik örüntüleri de ortaya çıkarıcı problem kurma çalışmaları yapılabilir. Bu çalışma problem çözme stratejilerinden örüntü arama stratejisi ile çözülebilecek problem kurma üzerinedir. Ileriye dönük yapılması planlanan çalışmalarda problem çözme stratejilerinden tablo yapma, bağıntı bulma gibi diğer stratejilerle çözülebilecek problem kurma çalışmaları yapılabilir. Bunun yanı sıra, problem kurma sırasında nasıl bir yol izledikleri, nelere dikkat ettikleri de araştırılabilir. Öğrencilerin sergilemiş oldukları performansta duyuşsal faktörler de etkili olmuş olabilir. Bu nedenle ilerleyen çalışmalarda öğrencilerin problem çözmeye ve kurmaya yönelik tutumları ile ilişkilendirilen çalışmalara da yer verilebilir.

\section{Kaynakça}

Abu-Elwan, R. (1999). The development of mathematical problem posing skills for prospective middle school teachers. In Mina, F.\& Rogerson, A. (Eds.) Paper presented at the proceedings of the International Conference on Mathematical Education into the 21st Century: Societal Challenges, Issues and Approaches, .(pp.1-8). Cairo, Egypt.

Burns, M. (2007). About teaching mathematics. Sausalito, CA:Math Solutions Publications.

Cankoy, O. \& Darbaz, S. (2010). Effect of a problem posing based problem solving instruction on understanding problem. Hacettepe University Education Faculty Journal, 38, 11-24.

Cathcart, W. G., Pothier, Y. M., Vance, J. H. \& Bezuk, N. S. (2003). Learning mathematics in elementary and middle schools. Upper Saddle River, N.J. : Merrill/Prentice Hall.

Christou, C., Mousoulides, N., Pittalis M., Pitta-Pantazi, D.\& Sriraman, B. (2005). An empirical taxonomy of problem posing process. ZDM Mathematics Education, 37 (3),149-158.

Çelik, A. Ve Yetkin-Özdemir, E.(2011). Illköğretim öğrencilerinin orantısal akıl yürütme becerileri ile oran-orant problemi kurma becerileri arasındaki ilişki. Pamukkale Üniversitesi Eğitim Fakültesi Dergisi, 30, 1-11.

Durmaz, B. ve Altun, M. (2014). Ortaokul öğrencilerinin problem çözme stratejilerini kullanma düzeyleri. Mehmet Akif Ersoy Üniversitesi Eğitim Fakültesi Dergisi, 30, 73 - 94.

Ev-Çimen, E. ve Yıldız, Ş. (2017). Ortaokul matematik ders kitaplarında yer verilen problem kurma etkinliklerinin incelenmesi. Turkish Journal of Computer and Mathematics Education. 8 (3), 378-407.

Gonzales, N. A. (1998). A blueprint for problem posing. School Science and Mathematics, 94(2), 78- 85.

Gür, H. \& Hangül, T. (2015). Ortaokul öğrencilerinin problem çözme stratejileri üzerine bir çalışma. Pegem Eğitim ve Öğretim Dergisi, 5(1), 95-112.

ışık, C. ve Kar, T. (2015). Altıncı sınıf öğrencilerinin kesirlerle ilgili açık-uçlu sözel hikayeye yönelik kurdukları problemlerin incelenmesi. Turkish Journal of Computer and Mathematics Education, 6(2), 230-249.

Kılıç, Ç. (2017). A new problem-posing approach based on problem-solving strategy: Analyzing pre-service primary school teachers' performance. Educational Sciences: Theory \& Practice, 17, 771-789.

MEB (2013). Ortaokul matematik dersi (5.,6.,7.ve 8. Sınıflar) öğretim programı. Ankara: MEB Basımevi. 
Miles M., \& Huberman, M.(1994). An expanded sourcebook qualitative data analysis (2nd Ed.). California: Sage Publications.

Mulligan, J. \& Mitchelmore, M. (2009). Awareness of pattern and structure in early mathematical development. Mathematics Education Research Journal, 21(2), 33-49.

Özgen, K., Aydın, M., Geçici, M.E. ve Bayram, B. (2017). Sekizinci sınıf öğrencilerinin problem kurma becerilerinin bazı değişkenler açısından incelenmesi. Turkish Journal of Computer and Mathematics Education 8(2), 323-351.

Pirie, S. E. B. 2002. Problem posing: What can it tell us about students' mathematical understanding, In Proceedings of the 24th Annual Meeting North American Chapter of the International group for the Psychology of Mathematics Education (pp. 925-958). GA, Athens.

Reys, R. E., Suydam, M. N., Lindquist, M. M. \&Smith, N. L. (1998). Helping children learn mathematics. Needham Heights: Allyn\&Bacon.

Silver, E. A. (1994). On mathematical problem posing. For the Learning of Mathematics,14(1), 19-28.

Silver, E. A. \& Cai, J. (1996). An analysis of arithmetic problem posing by middle school students. Journal for Research in Mathematics Education, 27(5), 521-539.

Smith, S. S. (1997). Early Childhood Mathematics. Needham Heights: Ally\&Bacon.

Smith,S.S. (2013).Early Childhood Mathematics. Boston, MA:Pearson

Souviney, R. J. (1994). Learning to teach mathematics. Englewood Cliffs: Macmillan Publishing Company.

Stacey, K. (1989). Finding and using patterns in linear generalizing problems. Educational Studies in Mathematics, 20, 147-164.

Stoyanova, E.\& Ellerton, N. F. (1996). A Framework for research into students' problem posing in school mathematics, In,Technology in Mathematics Education, ed. P. Clarkson, (pp.518-525) .Melbourne: Mathematics Education Research Group of Australasia.

Şengül-Akdemir, T. ve Türnüklü, E. (2017). Ortaokul 6. sınıf öğrencilerinin açılar ile ilgili problem kurma süreçlerinin incelenmesi. International Journal of New Trends in Arts, Sports \& Science Education, 6(2), 17-39.

Ticha, M.\&Hospesova, A. (2009). Problem posing and development of pedagogical content knowledge in pre-service teacher training. Paper presented in CERME 6. Lyon, France.

Van de Walle J. A. (2004). Elementary and Middle School Mathematics. Teaching Developmentally. Boston: Allyn \&Bacon.

Warren, E. \& Cooper, T. (2006). Using repeating patterns to explore functional thinking. APMC, 11 (1), 9-14. 